\title{
General Psychiatry Successful treatment of psychosis induced by interferon alpha and ribavirin with paliperidone: first case reported
}

\author{
Carmen Maura Carrillo de Albornoz Calahorro, ${ }^{1}$ Maria Isabel Navarrete Paez, ${ }^{1}$ \\ Margarita Guerrero Jimenez, ${ }^{1}$ Luis Gutierrez Rojas ${ }^{2}$
}

To cite: Carrillo de Albornoz Calahorro CM, Navarrete Paez MI, Guerrero Jimenez M, et al. Successful treatment of psychosis induced by interferon alpha and ribavirin with paliperidone: first case reported. General Psychiatry 2019;32:e100075. doi:10.1136/ gpsych-2019-100075

Received 02 April 2019 Revised 10 May 2019 Accepted 27 May 2019
Check for updates

(C) Author(s) (or their employer(s)) 2019. Re-use permitted under CC BY-NC. No commercial re-use. See rights and permissions. Published by BMJ.

${ }^{1}$ Psychiatry, Hospital Universitario Virgen de las Nieves, Granada, Spain ${ }^{2}$ Hospital Universitario San Cecilio, University of Granada, Granada, Spain

Correspondence to Carmen Maura Carrillo de Albornoz Calahorro, Psychiatry, Hospital Universitario Virgen de las Nieves, Granada 18014, Spain;

carmens_maura@hotmail.com

\section{ABSTRACT}

Several clinical studies have shown a large number of mental symptoms by immunomodulatory treatment with interferon (IFN). The most frequently described symptoms are depression, suicidal behaviour, manic symptoms, anxiety, psychosis and delirium, associated with other non-specific symptoms such as fatigue, irritability, psychomotor retardation, decreased libido, insomnia, difficulty in concentration and attention. Having a history of mental disorder contraindicates the use of IFN-alpha. These adverse effects that affect the mental state appear usually at the beginning of the treatment (most after 3 weeks of treatment). The incidence of psychotic episodes is low and the episodes usually remit when treatment is interrupted; only some cases require antipsychotic treatment. We present the case of a patient affected with hepatitis $\mathrm{C}$ who began to present self-referential delirious symptoms after receiving the treatment with IFN and who was successfully treated with paliperidone. This patient could be classified within the group of high-risk psychiatric patients given the family history of schizophrenia and his personal history of illegal drug consumption. The pharmacological actions of paliperidone are similar to other high potency atypical antipsychotics. The receptorbinding profile of paliperidone most closely resembles that of risperidone and ziprasidone. Paliperidone differs from risperidone and most other antipsychotics by its relatively low extent of enzymatic hepatic metabolism. To the best of our knowledge, this is the first case described that was successfully treated with paliperidone.

\section{INTRODUCTION}

Addictions and mental illness comorbidity are more frequent in patients with chronic hepatitis $\mathrm{C}$ than in the general population. In addition, the treatment with interferon alpha $($ IFN- $\alpha$ ) frequently results in psychiatric side effects, which are the risk factors for a failed treatment, leading to a major impact on the quality of life and reduction of therapeutic adherence. $^{12}$

Pegylated antiviral therapies and high-standard IFN in combination with ribavirin are frequently associated with psychiatric side effects, which can occur in $30 \%-80 \%$ of patients under treatment. ${ }^{3}$

Moderate depressive syndromes can appear in up to $70 \%$ of the cases and major depressive episodes around 15\%-45\%. Fatigue is the most prominent side effect, occurring in $80 \%$ of cases. Anger, irritability and/ or hostility have been described in $50 \%$ of treated patients. ${ }^{2}$ Alterations in sleep, anxiety, cognitive alterations can occur in $50 \%$ of cases. In contrast, mania and psychosis are very infrequent side effects, which can reach up to $3 \%$. Finally, suicidal thoughts have been described in $10 \%$ of patients under treatment with IFN- $\alpha$, with some cases of completed suicide. $^{4}$

Specifically, ribavirin is known to cause haemolytic anaemia, while boceprevir is associated with irritability, insomnia, anaemia and dysgeusia. ${ }^{5}$

There are some other risk factors which need to be contemplated such as previous history of affective disorder, sleep disturbances, advanced age, organic brain alteration (vascular pathology, AIDS encephalopathy, etc), together with limited social and functional support. ${ }^{4}$

Paliperidone, which is pharmacologically identical to 9-hydroxyrisperidone, exhibits high affinities for dopamine type 2 and serotonin 5-hydroxytryptamine-2 receptors but does not undergo significant hepatic metabolism. The drug is well tolerated in patients with poor hepatic function and seems unlikely to be susceptible to metabolic drug interactions. ${ }^{6}$

\section{CASE REPORT}

A 34-year-old man was referred to the mental health unit by the digestive system specialist. The patient presented psychotic symptoms 
after the treatment for hepatitis C virus (HCV) infection with pegylated IFN- $\alpha-2 b 3 \mathrm{MU}$, subcutaneously, 3 days a week and ribavirin in $200 \mathrm{mg}$ oral tablets at a dose of 1000 $\mathrm{mg} /$ day for 3 weeks.

\section{Personal history}

- Medical-surgical antecedents: chronic hepatopathy in cirrogenic evolution by HCV (genotype Ia).

- Illegal drugs: former illicit drug addict parenterally (heroin); former consumer of cocaine and cannabis. Follow-up by an illegal drug addiction centre since the age of 30 .

- Psychiatric antecedents: self-limited cocaine induced psychosis, which did not require treatment.

\section{Family background}

The patient's father had been diagnosed with non-specified psychosis, and his grandfather was diagnosed with schizophrenia.

\section{Current illness}

After the first 3 weeks of the administration of antiretroviral treatment, the patient began to present behavioural changes and sleep-wake inversion coexisting with decreased sleep needs. He exhibited delusions of persecution and filiation (asserting that he was not the biological son of his mother). He also showed an unstructured religious mystical ideation (he believed that he was involved in some divine plans).

He presented intrusive and ego-dystonic obsessive ideas, which he recognised as not very rational and contained sexual contents towards his grandmother, but these were not accompanied by compulsive behaviours. These ideas generated great anguish. He exhibited hallucinations in the form of voices that he recognised as his father and a psychologist who attended him years ago. He presented soliloquies (he had conversations about his work, his life with these people). For this reason, antiretroviral treatment was withdrawn, despite not having complied with the 48 weeks recommended duration. Undetectable viral load was not accomplished either. He was immediately referred to the mental health unit.

\section{Physical examination}

- Cardiopulmonary auscultation: within normality.

- Abdominal examination: hepatomegaly as the only remarkable finding

\section{Psychopathological exploration}

He was presented as a middle-aged man, with a careful and suitable behavioural appearance. He was conscious and oriented, and he was approachable and collaborative.

There was a slight decrease in attention and concentration.

Immediate memory did not present alterations. There was an increase in speech pressure. He exhibited delusional ideation of prejudice, filiation and poorly structured religious mystic themes. The mood was hyperthymic, with restlessness and without respecting the interpersonal distance, and slightly uninhibited. He exhibited auditory hallucinations in the second and third person and he displayed echo and thought phenomena. The patient verbalised obsessive ideas and delusional ideation of non-systematised persecution. There was no desire for death or tanatic ideation. He presented global insomnia and hyporexia. Null disease awareness at the moment.

\section{Supplementary tests}

- Haemogram: haematies $4950000 \mathrm{~mm}^{3}$; haemoglobin $16.5 \mathrm{~g} / \mathrm{L}$; haematocrit 48.4\%; mean corpuscular velocity $97.7 \mathrm{fL}$; mean corpuscular haemoglobin 33.4 pg; platelets $134 \times 10^{9} \mathrm{~g} / \mathrm{L}$; rest within normality.

- Biochemistry: aspartate transaminase $114 \mathrm{U} / \mathrm{L}$; alanine aminotransferase $177 \mathrm{U} / \mathrm{L}$; gamma-glutamyl transpeptidase $188 \mathrm{U} / \mathrm{L}$.

- Thyroid stimulating hormone: $3.2 \mathrm{mIU} / \mathrm{L}$; alfafetoprotein $2 \mu \mathrm{g} / \mathrm{L}$.

- Coagulation, lipid profile, vitamin B12 and folic acid: within normality.

- Serologies: syphilis, Borrelia, HIV, Epstein-Barr virus, cytomegalovirus and hepatitis B virus negative; positive HCV.

- Abdominal ultrasound: liver with a rough appearance, with somewhat irregular borders and left hepatic lobe enlarged, without space-occupying lesions; normal hepatopetal flow portal; rest without significant findings. The findings are suggestive of chronic hepatopathy in cirrogenic evolution.

\section{Diagnosis}

In our case, we detected delusional ideation of harm, filiation and religious mysticism, as well as hallucinations in the second and third person. The conscience was not affected.

He was diagnosed as IFN-induced and rivabirin-induced psychosis following the criteria for the suspected diagnosis of psychosis by IFN- $\alpha$ :

- Start of symptoms before 3 weeks of treatment.

- Family history of mental disorder.

- Personal history of psychosis, affective disorder, alterations in sleep, advanced age, organic brain alteration, toxic consumption.

- Key symptoms such as delusional ideation, thought disorders, hallucinations or affective alterations.

\section{Evolution and treatment}

The progressive increase of transaminases in the last 6 months required the choice of an antipsychotic avoiding hepatic metabolisation. Paliperidone extended release (ER) is an atypical antipsychotic that, unlike other antipsychotics, is not extensively metabolised in the liver. ${ }^{7}$ A pharmacokinetic analysis in patients with moderate hepatic impairment and healthy volunteers showed that unbound plasma concentrations of paliperidone ER were similar between the populations. ${ }^{8}$ Consequently, no dose adjustment is required in patients with mild or moderate hepatic impairment. ${ }^{9}$ 
Different studies suggest that paliperidone is well tolerated in patients with schizophrenia or schizoaffective disorder who have a stable active hepatic disease. ${ }^{10}$ Initially, he was treated with oral paliperidone in a dose of $6 \mathrm{mg} / 24$ hours and it was switched to intramuscular paliperidone palmitate after 14 days due to the patient's very poor oral medication adherence and good response to oral paliperidone. The psychotic symptomatology diminished until it was encapsulated. Previous treatment with methadone at $40 \mathrm{mg}$ was maintained.

The auditory hallucinations were translated in the chronic form but with very poor affective repercussion, except in moments of a lot of hallucinatory activities, in which the patient tended to isolate himself and he only responded to the auditory hallucinations that provoked him. These episodes lasted about 2 weeks and were resolved by temporarily increasing of the antipsychotic. The intercrisis periods lasted several months. The awareness of the disease had been increasing until the patient adequately criticised the psychotic symptoms, but the biographical rupture persisted after receiving antiretroviral treatment.

In the last 2 years, the progression of hepatopathy had produced asthenia and problems in the digestive sphere in the patient. He had a feeling of disability and incapacity with reactive hypotonia in this vital situation.

Currently, a treatment with paliperidone at a dose of 3 $\mathrm{mg} /$ day and methadone ratio of $40 \mathrm{mg} /$ day is ongoing.

The hallucinatory activity is chronic, although with little emotional repercussion, it is prescribed in the low doses (3 mg) of maintenance for the control of the symptomatology.

\section{DISCUSSION}

Approximately $13 \%$ of patients with $\mathrm{HCV}$ receiving treatment with IFN- $\alpha$ have neuropsychiatric symptoms such as depression, anxiety, suicidal ideation or psychosis; the latter is observed in $1 \%$ of the cases. ${ }^{1}$ Among the most frequent psychotic symptoms are the presence of auditory hallucinations and delusions of persecution. These symptoms have been recognised as a valid reason to interrupt the treatment, but there are cases in which the symptoms do not stop after removing it, despite receiving antipsychotics, as is the case with our patient. ${ }^{23}$

There are several proposed biological mechanisms underlying this proinflammatory-induced neurodegenerative effect including upregulation of the central serotonin transporter molecular, a decrease in neurogenesis in brain-neuronal circuits regulating mood, changes in tryptophan metabolism via activation of the enzyme indoleamine-D-oxygenase, changes in central glutamate metabolism, activation of the hypothalamic-pituitaryadrenal axis and alteration in cellular apoptosis mechanisms. How these mechanisms may interact is not clearly understood. ${ }^{11}$
In addition to the genetic and environmental risk factors for psychosis that our patient presents, has been able to favour the appearance of this disorder.

Regarding prevention, it would be a contribution to include the high psychiatric risk as a special group and study subjects. These high-risk groups must have psychological and psychiatric support at different times of treatment. Future studies should demonstrate efficient and effective models for research and longitudinal monitoring during the course of treatment, to standardise intervention and treatment models, in addition to focusing on extending management including depressive syndrome, evaluating anxious disorders, management of anger and mania and designing a multidisciplinary strategy to reduce the deterioration of the quality of life of these patients.

This is a clear example of how we underestimated correct anamnesis before selecting the treatment.

So far, this is the first published case found in a review through the PubMed search engine of psychosis secondary to treatment with IFN, and successfully treated with paliperidone.

Correction notice This article has been corrected since it was first published. The lead author's name was incorrectly listed in the author biography. This has been amended.

Funding The authors have not declared a specific grant for this research from any funding agency in the public, commercial or not-for-profit sectors.

Competing interests None declared.

Patient consent for publication Obtained.

Provenance and peer review Not commissioned; externally peer reviewed.

Open access This is an open access article distributed in accordance with the Creative Commons Attribution Non Commercial (CC BY-NC 4.0) license, which permits others to distribute, remix, adapt, build upon this work non-commercially, and license their derivative works on different terms, provided the original work is properly cited, appropriate credit is given, any changes made indicated, and the use is non-commercial. See: http://creativecommons.org/licenses/by-nc/4.0/.

\section{REFERENCES}

1. Cheng $\mathrm{Y}-\mathrm{C}$, Chen $\mathrm{C}-\mathrm{C}$, Ho A-S, et al. Prolonged psychosis associated with interferon therapy in a patient with hepatitis C: case study and literature review. Psychosomatics 2009;50:538-42.

2. Schafer M, Boetsch T, Laakmann G. Psychosis in a methadonesubstituted patient during interferon-alpha treatment of hepatitis $\mathrm{C}$. Addiction 2000;95:1101-4.

3. Schaefer M, Sarkar R, Diez-Quevedo C. Management of mental health problems prior to and during treatment of hepatitis $C$ virus infection in patients with drug addiction. Mental Heath and HCV in Drug Addiction 2013;7.

4. Horia GC, Dana CH, Bogdan N. Psychiatic adverse effects of interferon therapy. Clujul Medical 2013;86.

5. Budhram A, Cebrian C. Paranoid psychosis and cognitive impairment associated with hepatitis $C$ antiviral therapy. General Hospital Psychiatry 2014;36:126.e3-126.e5.

6. Marino J, Caballero J. Paliperidone extended-release for the treatment of schizophrenia. Pharmacotherapy 2008;28:1283-98.

7. Vermeir M, Naessens I, Remmerie B, et al. Absorption, metabolism, and excretion of paliperidone, a new monoaminergic antagonist, in humans. Drug Metab Dispos 2008;36:769-79.

8. Boom S, Thyssen A, Crauwels $\mathrm{H}$, et al. The influence of hepatic impairment on the pharmacokinetics of paliperidone. Int J Clin Pharmacol Ther 2009;47:606-16.

9. Paulzen M, Orfanos S, Gründer G. Remission of drug-induced hepatitis after switching from risperidone to paliperidone. Am J Psychiatry 2010;167:351-2. 
10. Amatniek J, Canuso CM, Deutsch SI, et al. Safety of paliperidone extended-release in patients with schizophrenia or schizoaffective disorder and hepatic disease. Clin Schizophr Relat Psychoses $2014 ; 8: 8-20$
11. Sundberg I, Lannergård $A$, Ramklint $M$, et al. Direct-acting antiviral treatment in real world patients with hepatitis $C$ not associated with psychiatric side effects: a prospective observational study. BMC Psychiatry 2018;18.

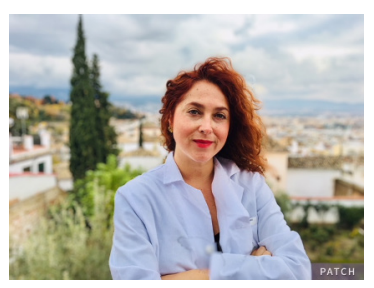

Carmen Maura Carrillo has acquired three university degrees from the University of Alcala de Henares in Mental Health Emergencies and Affective Disorders. She used to have clinical training at the San Cecilio Hospital in Granada, Spain, where she performed her first medical specialty via MIR for 4 years in general and community medicine. Afterwards, she had worked for 3 months in the Alto Guadalquivir High Resolution Hospital Complex as a specialist in the emergency department. Then she performed the specialisation via MIR in psychiatry in the Granada Sur Clinical Management Area, working a posteriori in the Community Mental Health Unit of the Baza region and in the Virgen de las Nieves Hospital in Granada. She is currently working as a psychiatric specialist in the Virgen de las Nieves Hospital in Granada, Spain. She has enjoyed two IFMSA scholarships for clinical stays in the cities of Tartu, Estonia (Tartu University Hospital) and Pilsen, Czech Republic (Pilsen University Hospital), and an academic scholarship within the Erasmus program in Milan. Currently she is completing her PhD in Clinical Medicine and Public Health under the line of research: clinical neuroscience and health. 